\section{Fertility of Mice treated with Phosphorus-32}

SINCE radioisotopes became available, many papers have been published concerning their clinical use as well es their potential harmful effects. One of these agents, phosphorus-32, is now occasionally being used in non-malignant conditions ; consequently an effect which may be irrelevant in a cancer petient may become important in a young person who is likely to survive for some years; for example, the effect on the gonads. Previous knowledge on the subject is somewhat confusing ${ }^{1-5}$, and no functional test has apparently been carried out so far.

The experiments reported here were carried out in $B A L B$ mice of both sexes, $1 \frac{1}{2}-5$ months old at the time of injection. Doses of phosphorus-32 ranging from 16 to $205 \mu \mathrm{c}$. were given intraperitoneally and the animals were mated with normal ones, previously checked for fertility, at periods of $1-8 \frac{1}{2}$ months after the administration of the agent. 3-12 months after treatment all the animals were killed and their ovaries and testes studied.

Tables 1 and 2 show the results obtained. $40 \mu \mathrm{c}$. seemed to be the threshold dose inducing sterility in all the females, since 6 of them so treated and mated with normal males revealed no pregnancy during 3-5 months of observation. With larger doses no pregnancies were encountered either, although the animals were kept under observation during periods up to 12 months. Males, however, were fertile even after receiving the largest dose administered, nomely, $205 \mu \mathrm{c}$., which killed 5 out of 8 animals of this group. Since they were observed during periods ranging from 3 to 12 months, it seems safe to conclude that no dose short of the lethal one is capable of inducing sterility in males, whereas females become sterile with doses much below the lethal ones (approximately one-third $L D 50$ ) and probably similar to those used in therapeutics.

Table 1. Balb fhmale Mroe treated with Phosphorus-32

\begin{tabular}{|c|c|c|}
\hline Dose $(\mu \mathrm{c})$. & No. of females treated & No. of females pregnant \\
\hline 16 & 2 & 2 \\
28 & 8 & 3 \\
34 & 5 & - \\
40 & 6 & - \\
60 & 6 & - \\
90 & 8 & - \\
200 & 3 & - \\
\hline
\end{tabular}

Table 2. Balb Male Mice treated with Phosphords-32

\begin{tabular}{|c|c|c|}
\hline Dose $(\mu \mathrm{c})$. & No. of males treated & No. of males fertile \\
\hline $40 \cdot 7$ & 1 & 1 \\
90 & 2 & 2 \\
106 & 1 & 1 \\
137 & 1 & 1 \\
205 & 3 & 3 \\
\hline
\end{tabular}

Ovaries and testes showed patterns generally in agreement with the observations of Bloom $^{1}$ and Odeblad $^{3}$. However, no reappearance of the pearl formation in the ovaries, as described by Warren et al. ${ }^{2}$, has been seen even 150 days after treatment. The results reported here seem to indicate that there is a real absence of oogenesis with doses of $40 \mu \mathrm{c}$. and not a decreased frequency as observed histologically by Warren et al. using much larger doses (250 and $2,000 \mu \mathrm{c}$.).

We are indebted to Fundaleu (Fundacion para combatir la leucemia), which partly supports the
Seccion Leucemia Experimental, the Comision Nacional de Energia Atomica, for supplying us the radioactive phosphorus used, and E. R. Squibb and Sons, Argentina S.A., which partly supported this investigation.

\section{E. A. D. Holmberg}

A. Pavlovsky

C. D. DE Pasqualini

Seccion Leucemia Experimental,

Instituto de Investigaciones Hematologicas,

Academia Nacionel de Medicina,

Melo 3081,

Buenos Aires.

\section{S. L. RABASA}

Instituto de Investigaciones Medicas, Rosario, Argentina.

${ }^{1}$ Bloom, W., NNES, Div. IV, 22, 1 (1948).

"Warren, S., MacMillan, J. C., and Dixon, F. J., Radiology, 55, 557 (1950).

${ }^{3}$ Odeblad, E., Acta Radiologica, 38, 33 (1952).

- Odeblad, E., Acta Radiologica, Supp. 93 (1952).

${ }^{5}$ Kawin, B., Hanford Atomic Products Operation, Richland, Washington (Nov. 21, 1958).

\section{ANATOMY}

\section{Pattern of Hxmopoiesis in the Fotal Liver}

WHILE the importance of the hæmopoietic role of the fotal liver is universally recognized, remarkably little precise information is evailable about the changing cytology of this organ during the course of development. The recent interest in techniques for the transfusion of suspensions of human foetal liver, as a source of hæmopoietic stem-cells, has, however, made it desirable to study more fully the processes of foetal blood formation.

We are investigating the development of the blood and blood-forming tissues in the human embryo and foetus, using quentitative methods wherever possible. In 35 fotuses, obtained by hysterotomy between the second and seventh months of pregnancy, the livers have been examined both in sections and in smears.

The composition of the hæmopoietic cell population of the liver differs in a striking fashion from that of the bone-marrow (Fig. 1), and it would appear that the pattern of hremopoiesis in the two situations is fundamentally different. Whereas the cytology of the bone-marrow suggests active erythropoiesis and granulopoiesis from the inception of the hæmopoietic process, that of the liver indicates an overwhelmingly erythropoietic pattern of hæmopoiesis and we can find no evidence of granulopoiesis. The occasional granulocytes which are observed in liver preparations are in all probability derived mainly from the blood. Bridges et al. ${ }^{1}$ administered a suspension of fotal liver to a patient suffering from pancytopenia, and afterwards observed a pronounced granulocytosis. It is possible, therefore, that the liver does in fact contain myeloblasts, which in situ fail to differentiate into granulocytes because of local metabolic conditions but which do so on reaching an eppropriate environment. The liver certainly contains a few cells which we would confidently label myeloblasts if we saw them in the bone-marrow.

The liver and bone-marrow also differ in their lymphocyte content. Although no evidence of lymphocytopoiesis can be found in even the earliest bonemarrow, about one quarter of its nucleated cells are 